\title{
Avaliação do teor de ferro e zinco e composição centesimal de farinhas de trigo e milho enriquecidas
}

\author{
Thaís Rezende Boen ${ }^{1}$, Bruno Thiago Soeiro' ${ }^{1}$ Edenir Rodrigues Pereira Filho², \\ Juliana Azevedo Lima-Pallone*1
}

'Pontifícia Universidade Católica de Campinas, CEATEC, Faculdade de Química, ${ }^{2}$ Universidade Federal de São Carlos, Departamento de Química

*Correspondência:

J. A. Lima-Pallone

Faculdade de Química

Pontifícia Universidade Católica de

Campinas

Rod. D. Pedro I, Km 136

13086-900 - Campinas - SP

E-mail: julianalima@puc-

campinas.edu.br
$O$ objetivo deste trabalho foi avaliar o teor de ferro e zinco e a composição centesimal de farinhas de trigo e milho enriquecidas. Para a avaliação das concentrações de ferro e zinco, aplicou-se a técnica de Espectrometria de Absorção Atômica com Chama. Foram utilizados os métodos oficiais de análise para a determinação de umidade, cinzas, proteinas, carboidratos e lipídeos. Os dados obtidos foram comparados aos valores declarados nos rótulos dos produtos e às especificações recomendadas pela Legislação Brasileira. A concentração de ferro estava acima do especificado para a maioria das amostras. O teor de zinco variou entre 0,6 e 1,5 mg/100 g. Constatou-se que todas as farinhas avaliadas apresentaram características físico-quimicas compativeis com a Legislação. Já em relação ao rótulo dos produtos, verificou-se haver variação entre os valores obtidos e aqueles apresentados na embalagem, para algumas amostras. Os resultados obtidos no trabalho são de grande importância para o alcance dos objetivos da obrigatoriedade do enriquecimento de farinhas.

\section{INTRODUÇÃO}

A fortificação de alimentos com nutrientes é uma prática aceita e empregada pelos processadores de alimentos desde a metade do século XX (Reilly, 1996) e tem como objetivo reforçar o valor nutritivo e prevenir ou corrigir deficiências de um ou vários nutrientes (ANVISA, 2006). No Brasil, a Resolução RDC 344, de 13 de dezembro de 2002 , instituiu que desde junho de 2004, as farinhas de trigo e milho deveriam ser enriquecidas com ácido fólico (150 mg/100 g de farinha) e ferro $(4,2 \mathrm{mg} / 100 \mathrm{~g}$ de fari- nha). O objetivo dessa obrigatoriedade é a prevenção de anemia ferropriva e de defeitos no fechamento do tubo neural (ANVISA, 2006).

A qualidade das farinhas é determinada por variedade de características, que podem ser classificadas em físicas, químicas, enzimáticas e funcionais (Rasper, 1991). Dentre as características físicas e químicas, o estabelecimento da composição centesimal está diretamente relacionado à classificação desses produtos, em relação aos padrões de qualidade e identidade. O teor de cinzas, por exemplo, tem a função de classificação para farinhas de trigo e indica a presença 
de sais minerais contidos no pericarpo e nas primeiras camadas do grão de trigo. Determinam, portanto, o grau de extração e a presença de farelo (ANVISA, 2006). Para o caso especial de farinhas enriquecidas com vitaminas e minerais, os componentes majoritários podem influenciar diretamente na manutenção dos micronutrientes, principalmente durante a estocagem desses produtos. Nesse aspecto, o teor de umidade, por exemplo, é muito importante, por ser um dos principais fatores de aceleração de reações químicas e enzimáticas (Gutkoski, Jacobsen Neto, 2002).

De acordo com estimativa do Ministério da Saúde, cerca de $45 \%$ das crianças brasileiras de até 5 anos (10 milhões de pessoas) têm anemia (ANVISA, 2006). As conseqüências fisiológicas são insuficiência no transporte de oxigênio, no metabolismo oxidativo, no metabolismo nuclear e na descrição de genes, causando desde prejuízos no desenvolvimento intelectual e comportamental, até baixas na resistência imunológica (Tapieiro et al., 1991). Por outro lado, o ferro tem sido apontado como um dos promotores do estresse oxidativo (Jenner, Olanow, 1996). Doenças já consagradas como conseqüentes ao estresse oxidativo são a doença de Parkinson, a doença de Alzheimer, o acidente vascular cerebral, a esclerose múltipla e a catarata, entre outras (Ferreira, Matsubara, 1997).

Para a fortificação de farinhas, a mesma Resolução mencionada anteriormente, permite a utilização de compostos de grau alimentício na forma de sulfato ferroso, ferro reduzido (325 mesh Tyler), ferro eletrolítico (325 mesh Tyler), EDTA de ferro e sódio, ferro bisglicina quelato e outros compostos de biodisponibilidade não inferior à dos compostos permitidos (ANVISA, 2006).

Estudos realizados por diversos pesquisadores indicam, entretanto, que a suplementação com ferro pode comprometer a biodisponibilidade do zinco no organismo humano (Pedrosa, Cozzolino, 1993; Lobo, Tramonte, 2004), já que existe interação competitiva, fundamentada na similaridade química entre eles (Solomons, 1986). O zinco possibilita várias funções bioquímicas, pois é componente de inúmeras enzimas. Participa na divisão celular, expressão genética, processos fisiológicos como crescimento e desenvolvimento, na transcrição genética, na morte celular, age como estabilizador de estruturas de membranas e componentes celulares, além de participar da função imune e desenvolvimento cognitivo (Henriques et al., 2003; Sena, Pedrosa, 2005). Alguns trabalhos disponíveis na literatura apontam a proporção em torno de 4:1 (Fe:Zn) como desfavorável para o aproveitamento do zinco (Pedrosa, Cozzolino, 1993).

Dessa forma, o objetivo do presente trabalho foi avaliar a concentração de ferro e zinco e a composição centesimal de farinhas de trigo e milho enriquecidas.

\section{MATERIAL E MÉTODOS}

\section{Produtos avaliados}

Foram empregadas 3 diferentes marcas de farinhas de trigo tipo especial (FT) e de milho flocada (FM) enriquecidas com ferro e ácido fólico disponíveis comercialmente na cidade de Campinas. Foram avaliadas 3 marcas (A, B, C), em 5 lotes $(1,2,3,4,5)$. As farinhas de trigo foram inicialmente homogeneizadas e, posteriormente amostradas em quarteador ( 3 bandejas, Metalúrgica Leonardo), com a obtenção de aproximadamente $100 \mathrm{~g}$ de amostra para as análises. Para as farinhas de milho flocadas foi necessário efetuar-se a moagem (Moinho Ika, modelo A11), em laboratório e peneiramento (28 Mesh, Bertel), antes da retirada de amostras para as análises. Seguiram-se as determinações de ferro, zinco, umidade, cinzas, proteínas, lipídeos e carboidratos em amostras de farinhas de trigo (FT) e milho (FM).

\section{Análise da composição centesimal}

\section{Determinação de umidade (AOAC, 1997)}

O método utilizado foi o de secagem em estufa $\left(105^{\circ} \mathrm{C} \pm 5^{\circ} \mathrm{C}\right)$, baseado na remoção da água por aquecimento. As amostras foram colocadas em cadinhos de alumínio, com massas previamente determinadas, ficando em estufa até a secagem. Os cadinhos contendo as amostras foram, então, resfriados à temperatura ambiente, em dessecador, tendo sua massa novamente determinada. Logo após, os cadinhos retornaram à estufa e este procedimento foi repetido até a obtenção de massa constante (por aproximadamente $5 \mathrm{~h}$ ). Foi calculada, então, a porcentagem de umidade nas farinhas. Todas as determinações foram feitas em triplicatas.

\section{Determinação de Cinzas (AOAC,1997)}

O método empregado foi o da incineração em mufla, no qual toda a matéria orgânica foi queimada. Cada amostra foi colocada em um cadinho de porcelana, com massa previamente estabelecida e permaneceu na mufla $\left(550{ }^{\circ} \mathrm{C}\right.$ $\pm 5^{\circ} \mathrm{C}$ ) até total queima da matéria orgânica. A diferença entre a massa da amostra mais cadinho e a massa do cadinho forneceu a massa das cinzas da amostra. Todas as determinações foram feitas em triplicatas.

\section{Determinação de proteínas (AOAC,1997)}

A determinação de proteínas foi realizada pelo método de Kjeldahl, no qual avaliou-se o teor de nitrogênio total de origem orgânica, utilizando-se $0,3 \mathrm{~g}$ de amostra em tubo para digestão. O procedimento do método baseou-se na di- 
gestão da amostra com ácido sulfúrico e mistura catalisadora contendo sulfato de cobre e sulfato de potássio para acelerar a reação. Assim, todo o carbono e hidrogênio foram oxidados a gás carbônico e água. O nitrogênio da proteína foi reduzido e transformado em sulfato de amônio. Destilou-se a amostra digerida em meio básico por adição de hidróxido de sódio $40 \%$, para a liberação da amônia. A amônia foi recolhida em solução de ácido bórico, formando borato de amônio. O borato de amônio formado foi quantificado por titulação com ácido clorídrico padronizado com carbonato de sódio. Utilizou-se o fator de conversão de 5,70 para farinhas de trigo e 6,25 para farinhas de milho. Todas as determinações foram feitas em triplicatas.

\section{Determinação de lipídeos (AOAC,1997)}

O método utilizado baseia-se em uma extração de gordura a frio utilizando mistura de três solventes, clorofórmio-metanol-água, em proporção na qual os três solventes formam solução homogênea. Para a determinação de lipídeos $4,0 \mathrm{~g}$ da amostra foram colocadas em tubos de ensaio e adicionou-se clorofórmio, metanol e água destilada. Os tubos foram tampados hermeticamente e agitados por trinta minutos. Adicionou-se, então, mais clorofórmio e solução de sulfato de sódio 1,5\% e agitou-se por mais dois minutos. Ocorreu, então, a separação total do clorofórmio, o qual carregou os lipídeos (camada inferior do tubo) e foi transferido para um béquer. O solvente foi eliminado por evaporação em estufa a $60{ }^{\circ} \mathrm{C}$. O resultado quantitativo foi calculado através da diferença entre o béquer vazio e o béquer contendo a solução evaporada de lipídeos. Todas as determinações foram feitas em triplicatas.

\section{Determinação de carboidratos (AOAC,1997)}

O conteúdo de carboidratos foi determinado por diferença: calculou-se a média da porcentagem de água, proteínas, lipídeos e cinzas e o restante foi considerado carboidrato. Todas as determinações foram feitas em triplicatas.

\section{Determinação de ferro e zinco}

Cerca de 0,2000 a 0,3000 g de farinhas de trigo e milho foram colocadas em papéis vegetais e depois transferidas para tubos de digestão. Adicionaram-se aos tubos $2 \mathrm{~mL}$ de ácido nítrico concentrado. Foram preparados, também, dois tubos "brancos" (sem as amostras).

Posicionaram-se pequenos funis na entrada de cada tubo de digestão, os quais foram levados ao bloco digestor, iniciando-se o aquecimento até a temperatura de $100{ }^{\circ} \mathrm{C}$, mantendo-se essa condição por $2 \mathrm{~h}$. Os funis permitiram que o ácido nítrico ficasse em refluxo. Após o resfriamento adicionou-se, $1 \mathrm{~mL}$ de peróxido de hidrogênio em cada tubo (inclusive nos brancos) e levou-se os tubos, novamente, para o bloco digestor, ajustando-se a temperatura para $110{ }^{\circ} \mathrm{C}$, por $30 \mathrm{~min}$. Aumentou-se a temperatura para $130^{\circ} \mathrm{C}$ e deixou-se por mais $1 \mathrm{~h}$. Retiraram-se os tubos do bloco e aguardou-se o resfriamento. Adicionou-se, posteriormente, pequena quantidade de água $(5 \mathrm{~mL})$ aos tubos. Deixou-se os tubos em um banho de ultra-som por alguns segundos e o conteúdo dos tubos foi transferido para balões volumétricos de $25 \mathrm{~mL}$, completando-se o volume com água. As determinações de ferro e zinco foram feitas em triplicatas, utilizando-se a técnica de Espectrometria de Absorção Atômica com Chama.

\section{RESULTADOS E DISCUSSÃO}

Nas Tabelas I, II e III podem ser observados os resultados obtidos para a determinação da composição centesimal, para 3 marcas (A, B e C) de farinhas de trigo (FT), em 5 diferentes lotes $(1,2,3,4$ e 5$)$ e os valores declarados nos rótulos de cada produto. De maneira geral, verificou-se que houve pequena variação para o teor de proteínas, lipídeos, umidade, cinzas e, conseqüentemente, carboidratos, entre os 5 diferentes lotes de farinhas de trigo, para as 3 marcas avaliadas. A principal divergência entre os valores foi observada para o teor de cinzas.

Para as avaliações individuais verificou-se que para as FT A (1-5) apenas os valores para proteínas e carboidratos estão de acordo com o rótulo. O teor de lipídeos apresentado $(0 \%)$ está em desacordo com o valor obtido, para os 5 diferentes lotes da marca (em média 1,37\%, em base seca). A porcentagem de cinzas, obtida experimentalmente, está abaixo do valor declarado pelo fabricante. Para as FT B (1-5) os valores apresentados na embalagem, para lipídeos, umidade e carboidratos está bem próximo daqueles obtidos após análises. Entretanto, o teor de proteínas está abaixo e o teor de cinzas está acima daqueles obtidos em laboratório. Para FT C (1-5) observou-se o mesmo comportamento encontrado para FT B.

Após a análise de variância (Programa Origin 6.1) constatou-se haver diferença significativa entre o teor médio de lipídeos, umidade e carboidratos e não houve diferença significativa entre os valores obtidos para proteínas e cinzas, entre as diferentes marcas, com $95 \%$ de probabilidade. Apesar dessas diferenças todas as amostras avaliadas no trabalho seguem, em média (teor de cinzas de $0,67 \% \pm 0,02$, proteínas $11,9 \% \pm 0,02$, em base seca), as normas, divulgadas pela portaria de $\mathrm{n}^{\circ} 354$ de 1996 (ANVISA, 2006), que caracterizam a farinha de trigo, classificada como especial, para uso doméstico, por teor de cinzas de $0,65 \% \mathrm{e}$ porcentagem de proteínas superior a $7 \%$, sendo esses valores em base seca. A umidade não deve exceder 15\%. 
TABELA I - Composição centesimal obtida experimentalmente e valores declarados nos rótulos de farinhas de trigo FT A

\begin{tabular}{|c|c|c|c|c|c|}
\hline $\begin{array}{l}\text { Farinha de } \\
\text { trigo } \\
\text { Marca/Lote }\end{array}$ & \multicolumn{5}{|c|}{$\begin{array}{l}\text { Composição centesimal obtida Composição centesimal } \\
\text { Análise } \quad \mathrm{M} \quad \% \mathrm{CV} \quad \begin{array}{l}\text { declarada no rótulo } \\
\text { das farinhas de trigo }\end{array}\end{array}$} \\
\hline FT A 1 & $\begin{array}{l}\text { Proteínas } \\
\text { Lipídeos } \\
\text { Umidade } \\
\text { Cinzas } \\
\text { Carboidratos }\end{array}$ & $\begin{array}{c}10,86 \\
1,21 \\
11,05 \\
0,59 \\
76,29\end{array}$ & $\begin{array}{l}1,4 \\
4,5 \\
0,2 \\
3,9 \\
0,1\end{array}$ & & \\
\hline FT A 2 & $\begin{array}{l}\text { Proteínas } \\
\text { Lipídeos } \\
\text { Umidade } \\
\text { Cinzas } \\
\text { Carboidratos }\end{array}$ & $\begin{array}{c}10,25 \\
1,17 \\
11,69 \\
0,66 \\
76,22\end{array}$ & $\begin{array}{l}1,5 \\
2,8 \\
0,2 \\
1,8 \\
0,1\end{array}$ & & \\
\hline FT A 3 & $\begin{array}{l}\text { Proteínas } \\
\text { Lipídeos } \\
\text { Umidade } \\
\text { Cinzas } \\
\text { Carboidratos }\end{array}$ & $\begin{array}{c}10,25 \\
1,29 \\
12,54 \\
0,43 \\
75,49\end{array}$ & $\begin{array}{l}1,4 \\
6,0 \\
0,1 \\
2,7 \\
0,1\end{array}$ & $\begin{array}{l}\text { Proteínas } \\
\text { Lipídeos } \\
\text { Umidade } \\
\text { Cinzas } \\
\text { Carboidratos }\end{array}$ & $\begin{array}{l}10 \\
0 \\
13 \\
0,8 \\
76\end{array}$ \\
\hline FT A 4 & $\begin{array}{l}\text { Proteínas } \\
\text { Lipídeos } \\
\text { Umidade } \\
\text { Cinzas } \\
\text { Carboidratos }\end{array}$ & $\begin{array}{c}10,44 \\
1,18 \\
12,46 \\
0,59 \\
75,33\end{array}$ & $\begin{array}{l}0,1 \\
1,3 \\
0,2 \\
2,7 \\
0,1\end{array}$ & & \\
\hline FT A 5 & $\begin{array}{l}\text { Proteínas } \\
\text { Lipídeos } \\
\text { Umidade } \\
\text { Cinzas } \\
\text { Carboidratos }\end{array}$ & $\begin{array}{c}10,39 \\
1,17 \\
12,34 \\
0,61 \\
75,49\end{array}$ & $\begin{array}{l}0,6 \\
0,4 \\
0,4 \\
2,3 \\
0,1\end{array}$ & & \\
\hline
\end{tabular}

M - média; \% CV - coeficiente de variação; FT - farinha de trigo, FT A - marca, FT A (1-5) - lote

Nas Tabelas IV, V e VI estão apresentados os dados obtidos após a determinação experimental de proteínas, lipídeos, umidade, cinzas e carboidratos, bem como os valores declarados nos rótulos das farinhas de milho flocadas (FM). Foram avaliadas 3 marcas (A, B e C), em 5 diferentes lotes $(1,2,3$, 4 e 5). Observou-se que para FM A (1-5) os valores obtidos para umidade e carboidratos estão de acordo com aqueles informados pelo fabricante. Entretanto, o teor de proteínas e cinzas estão abaixo e os valores para lipídeos estão acima, quando comparados ao rótulo $(7,4,0,6$ e $0 \%$ para proteínas, cinzas e lipídeos, respectivamente). Para FM B (1-5) a porcentagem de proteínas está $16 \%$, aproximadamente, abaixo e o teor de carboidratos está acima, daqueles valores observados na embalagem. Para os demais componentes, as porcentagens obtidas em laboratório estão muito próximas, em média, aos valores informados pelo fabricante. Para FM C (1-5), apenas o teor de cinzas
TABELA II - Composição centesimal obtida experimentalmente e valores declarados nos rótulos de farinhas de trigo FT B

\begin{tabular}{|c|c|c|c|c|c|}
\hline $\begin{array}{l}\text { Farinha de } \\
\text { trigo } \\
\text { Marca/Lote }\end{array}$ & $\begin{array}{l}\text { Composição c } \\
\text { Análise }\end{array}$ & $\begin{array}{c}\text { tesime } \\
\mathrm{M}\end{array}$ & $\begin{array}{l}\text { obtida } \\
\% \mathrm{CV}\end{array}$ & $\begin{array}{l}\text { omposição cen } \\
\text { declarada no } \\
\text { das farinhas de }\end{array}$ & $\begin{array}{l}\text { esimal } \\
\text { ótulo } \\
\text { trigo }\end{array}$ \\
\hline FT B 1 & $\begin{array}{l}\text { Proteínas } \\
\text { Lipídeos } \\
\text { Umidade } \\
\text { Cinzas } \\
\text { Carboidratos }\end{array}$ & $\begin{array}{c}10,35 \\
1,21 \\
12,94 \\
0,63 \\
74,87\end{array}$ & $\begin{array}{l}1,4 \\
4,5 \\
0,2 \\
0,8 \\
0,1\end{array}$ & \multirow{5}{*}{$\begin{array}{l}\text { Proteínas } \\
\text { Lipídeos } \\
\text { Umidade } \\
\text { Cinzas } \\
\text { Carboidratos }\end{array}$} & \\
\hline FT B 2 & $\begin{array}{l}\text { Proteínas } \\
\text { Lipídeos } \\
\text { Umidade } \\
\text { Cinzas } \\
\text { Carboidratos }\end{array}$ & $\begin{array}{c}9,92 \\
1,17 \\
12,99 \\
0,61 \\
75,31\end{array}$ & $\begin{array}{l}0,0 \\
2,8 \\
0,8 \\
1,8 \\
0,1\end{array}$ & & \\
\hline FT B 3 & $\begin{array}{l}\text { Proteínas } \\
\text { Lipídeos } \\
\text { Umidade } \\
\text { Cinzas } \\
\text { Carboidratos }\end{array}$ & $\begin{array}{c}10,27 \\
1,29 \\
13,22 \\
0,59 \\
74,64\end{array}$ & $\begin{array}{l}1,4 \\
6,0 \\
0,4 \\
1,0 \\
0,1\end{array}$ & & $\begin{array}{l}9,8 \\
1,4 \\
13 \\
0,8 \\
75,2\end{array}$ \\
\hline FT B 4 & $\begin{array}{l}\text { Proteínas } \\
\text { Lipídeos } \\
\text { Umidade } \\
\text { Cinzas } \\
\text { Carboidratos }\end{array}$ & $\begin{array}{c}10,27 \\
1,49 \\
12,58 \\
0,62 \\
75,04\end{array}$ & $\begin{array}{l}1,6 \\
1,7 \\
0,4 \\
3,6 \\
0,1\end{array}$ & & \\
\hline FT B 5 & $\begin{array}{l}\text { Proteínas } \\
\text { Lipídeos } \\
\text { Umidade } \\
\text { Cinzas } \\
\text { Carboidratos }\end{array}$ & $\begin{array}{c}10,32 \\
1,43 \\
13,23 \\
0,62 \\
74,39\end{array}$ & $\begin{array}{l}0,8 \\
2,0 \\
0,1 \\
0,8 \\
0,1\end{array}$ & & \\
\hline
\end{tabular}

$\mathrm{M}$ - média; \% CV - coeficiente de variação; FT - farinha de trigo, FT B - marca, FT B (1-5) - lote

médio obtido difere do valor da embalagem, estando abaixo da porcentagem declarada no rótulo.

Entretanto, apesar das diferenças encontradas entre marcas e lotes, a média dos valores obtidos para a composição centesimal nas amostras está de acordo com a Resolução ${ }^{\circ}$ 12, de 1978 (ANVISA, 2005) que permite até 1\% de cinzas, em farinhas de milho, em base seca. Os valores determinados para umidade e proteínas $(11,6 \%$ e 6,6\%) também previstos na mesma resolução como parâmetros de qualidade de farinhas de milho são $14 \%$ e $6 \%$ (em base seca). Portanto, as farinhas avaliadas estavam, de maneira geral, de acordo com as especificações. Após análise de variância (programa Origin 6.1) verificou-se haver diferença significativa entre as porcentagens de lipídeos, umidade, cinzas e carboidratos, entretanto, para proteínas os valores não diferiram de forma significativa entre as marcas, com $95 \%$ de probabilidade. 
TABELA III - Composição centesimal obtida experimentalmente e valores declarados nos rótulos de farinhas de trigo FT C

\begin{tabular}{|c|c|c|c|c|c|}
\hline $\begin{array}{l}\text { Farinha de } \\
\text { trigo } \\
\text { Marca/Lote }\end{array}$ & $\begin{array}{l}\text { Composição c } \\
\text { Análise }\end{array}$ & $\begin{array}{c}\text { ntesima } \\
\mathrm{M}\end{array}$ & $\begin{array}{l}\text { obtida } \\
\% \mathrm{CV}\end{array}$ & $\begin{array}{l}\text { omposição cent } \\
\text { declarada no } \\
\text { das farinhas de }\end{array}$ & $\begin{array}{l}\text { esimal } \\
\text { stulo } \\
\text { trigo }\end{array}$ \\
\hline FT C 1 & $\begin{array}{l}\text { Proteínas } \\
\text { Lipídeos } \\
\text { Umidade } \\
\text { Cinzas } \\
\text { Carboidratos }\end{array}$ & $\begin{array}{c}11,38 \\
1,49 \\
12,72 \\
0,55 \\
73,86\end{array}$ & $\begin{array}{l}1,4 \\
2,6 \\
0,1 \\
3,2 \\
0,1\end{array}$ & & \\
\hline FT C 2 & $\begin{array}{l}\text { Proteínas } \\
\text { Lipídeos } \\
\text { Umidade } \\
\text { Cinzas } \\
\text { Carboidratos }\end{array}$ & $\begin{array}{c}10,45 \\
1,48 \\
12,66 \\
0,55 \\
74,86\end{array}$ & $\begin{array}{l}1,4 \\
2,6 \\
0,7 \\
0,9 \\
0,1\end{array}$ & & \\
\hline FT C 3 & $\begin{array}{l}\text { Proteínas } \\
\text { Lipídeos } \\
\text { Umidade } \\
\text { Cinzas } \\
\text { Carboidratos }\end{array}$ & $\begin{array}{c}10,53 \\
1,45 \\
12,57 \\
0,60 \\
74,85\end{array}$ & $\begin{array}{l}1,4 \\
1,8 \\
0,2 \\
0,8 \\
0,1\end{array}$ & $\begin{array}{l}\text { Proteínas } \\
\text { Lipídeos } \\
\text { Umidade } \\
\text { Cinzas } \\
\text { Carboidratos }\end{array}$ & $\begin{array}{l}9,8 \\
1,4 \\
13 \\
0,8 \\
75,2\end{array}$ \\
\hline FT C 4 & $\begin{array}{l}\text { Proteínas } \\
\text { Lipídeos } \\
\text { Umidade } \\
\text { Cinzas } \\
\text { Carboidratos }\end{array}$ & $\begin{array}{c}10,09 \\
1,58 \\
11,82 \\
0,64 \\
75,87\end{array}$ & $\begin{array}{l}1,3 \\
2,3 \\
4,9 \\
3,8 \\
0,1\end{array}$ & & \\
\hline FT C 5 & $\begin{array}{l}\text { Proteínas } \\
\text { Lipídeos } \\
\text { Umidade } \\
\text { Cinzas } \\
\text { Carboidratos }\end{array}$ & $\begin{array}{c}10,49 \\
1,15 \\
12,65 \\
0,51 \\
75,20\end{array}$ & $\begin{array}{l}0,8 \\
1,1 \\
0,3 \\
2,4 \\
0,1\end{array}$ & & \\
\hline
\end{tabular}

$\mathrm{M}$ - média; \% CV - coeficiente de variação; FT - farinha de trigo, FT $\mathrm{C}$ - marca, FT C (1-5) - lote

As diferenças observadas na composição centesimal entre lotes e marcas de farinhas de milho e entre lotes e marcas de farinhas de trigo, devem-se, provavelmente, a diferentes condições de clima e tipos de solo durante o cultivo, variedade do grão, além de pequenas variações envolvidas na moagem e estocagem da matéria-prima, até a obtenção de cada um dos tipos de farinha.

Quanto às determinações de ferro e zinco, os resultados obtidos para as farinhas de trigo e milho encontramse na Figura 1. De acordo com a Tabela de Composição de Alimentos (TACO, 2006) o teor de ferro naturalmente presente em farinhas é de $1,0 \mathrm{mg} / 100 \mathrm{~g}$ e $0,9 \mathrm{mg} / 100 \mathrm{~g}$ para de trigo e milho, respectivamente. Observa-se, então, que a concentração de ferro $(4,1$ a $10,0 \mathrm{mg} / 100 \mathrm{~g}$,em média, $7,3 \mathrm{mg} / 100 \mathrm{~g}$ ) está acima dos valores declarados pelos fabricantes e indicados na Resolução 344 (4,2 mg/100 g). Já a concentração de zinco nas mesmas farinhas variou entre
TABELA IV - Composição centesimal obtida e valores declarados nos rótulos de farinhas de milho FM A

\begin{tabular}{|c|c|c|c|c|c|}
\hline $\begin{array}{l}\text { Farinha de } \\
\text { milho } \\
\text { Marca/Lote }\end{array}$ & \multicolumn{5}{|c|}{$\begin{array}{l}\text { Composição centesimal obtida Composição centesimal } \\
\text { Análise } \quad \mathrm{M} \quad \% \mathrm{CV} \quad \begin{array}{r}\text { declarada no rótulo } \\
\text { das farinhas de milho }\end{array}\end{array}$} \\
\hline 'FM A 1 & $\begin{array}{l}\text { Proteínas } \\
\text { Lipídeos } \\
\text { Umidade } \\
\text { Cinzas } \\
\text { Carboidratos }\end{array}$ & $\begin{array}{c}6,86 \\
1,07 \\
10,78 \\
0,32 \\
80,96\end{array}$ & $\begin{array}{l}2,1 \\
7,1 \\
0,2 \\
9,9 \\
0,1\end{array}$ & & \\
\hline FM A 2 & $\begin{array}{l}\text { Proteínas } \\
\text { Lipídeos } \\
\text { Umidade } \\
\text { Cinzas } \\
\text { Carboidratos }\end{array}$ & $\begin{array}{c}6,34 \\
1,06 \\
11,36 \\
0,37 \\
80,86\end{array}$ & $\begin{array}{l}2,4 \\
8,3 \\
0,7 \\
3,6 \\
0,1\end{array}$ & & \\
\hline FM A 3 & $\begin{array}{l}\text { Proteínas } \\
\text { Lipídeos } \\
\text { Umidade } \\
\text { Cinzas } \\
\text { Carboidratos }\end{array}$ & $\begin{array}{c}6,42 \\
0,97 \\
11,16 \\
0,31 \\
81,13\end{array}$ & $\begin{array}{l}2,5 \\
3,2 \\
0,3 \\
5,5 \\
0,1\end{array}$ & $\begin{array}{l}\text { Proteínas } \\
\text { Lipídeos } \\
\text { Umidade } \\
\text { Cinzas } \\
\text { Carboidratos }\end{array}$ & $\begin{array}{l}7,4 \\
0 \\
11 \\
0,6 \\
82\end{array}$ \\
\hline FM A 4 & $\begin{array}{l}\text { Proteínas } \\
\text { Lipídeos } \\
\text { Umidade } \\
\text { Cinzas } \\
\text { Carboidratos }\end{array}$ & $\begin{array}{c}6,43 \\
0,83 \\
9,72 \\
0,27 \\
82,74\end{array}$ & $\begin{array}{l}2,3 \\
4,7 \\
7,5 \\
4,6 \\
2,3\end{array}$ & & \\
\hline FM A 5 & $\begin{array}{l}\text { Proteínas } \\
\text { Lipídeos } \\
\text { Umidade } \\
\text { Cinzas } \\
\text { Carboidratos }\end{array}$ & $\begin{array}{c}6,60 \\
0,73 \\
11,64 \\
0,29 \\
80,73\end{array}$ & $\begin{array}{l}2,3 \\
2,4 \\
0,3 \\
5,5 \\
0,1\end{array}$ & & \\
\hline
\end{tabular}

M - média; \% CV - coeficiente de variação; FM - farinha de milho, FM A - marca, FM A (1-5) - lote

0,6 a 1,5 mg/100 g (em média, 1,1 mg/100 g). Esses valores são superiores aos apresentados na mesma Tabela de Composição de Alimentos $(0,8 \mathrm{mg} / 100 \mathrm{~g})$.

Um dado de grande relevância, obtido no trabalho, é a relação entre ferro e zinco, em média, 7:1, o que pode ser desfavorável para o aproveitamento do zinco. Além disso, os altos valores encontrados para a concentração de ferro nas amostras também são preocupantes, devido às propriedades oxidantes do ferro, relacionadas a diversos problemas de saúde.

Outro aspecto negativo está relacionado a possíveis estudos epidemiológicos que poderiam ser prejudicados, já que a concentração do mineral nas amostras avaliadas está acima dos níveis esperados. Portanto, a correlação do enriquecimento de farinhas com a possível diminuição da incidência de anemia, provocada pela carência de ferro, poderá levar a conclusões equivocadas, já que a concentra- 
TABELA V - Composição centesimal obtida e valores declarados nos rótulos de farinhas de milho FM B

\begin{tabular}{|c|c|c|c|c|c|}
\hline $\begin{array}{l}\text { Farinha de } \\
\text { milho } \\
\text { Marca/Lote }\end{array}$ & $\begin{array}{l}\text { Composição } \\
\text { Análise }\end{array}$ & $\begin{array}{l}\text { ntesim } \\
\mathrm{M}\end{array}$ & $\begin{array}{l}\text { obtida } \\
\% \mathrm{CV}\end{array}$ & $\begin{array}{l}\text { Composição cen } \\
\text { declarada no } \\
\text { das farinhas de }\end{array}$ & $\begin{array}{l}\text { esimal } \\
\text { ótulo } \\
\text { milho }\end{array}$ \\
\hline FM B 1 & $\begin{array}{l}\text { Proteínas } \\
\text { Lipídeos } \\
\text { Umidade } \\
\text { Cinzas } \\
\text { Carboidratos }\end{array}$ & $\begin{array}{c}6,65 \\
2,50 \\
11,69 \\
0,47 \\
78,69\end{array}$ & $\begin{array}{l}2,7 \\
1,0 \\
0,2 \\
2,9 \\
0,2\end{array}$ & & \\
\hline FM B 2 & $\begin{array}{l}\text { Proteínas } \\
\text { Lipídeos } \\
\text { Umidade } \\
\text { Cinzas } \\
\text { Carboidratos }\end{array}$ & $\begin{array}{c}6,70 \\
2,58 \\
11,95 \\
0,68 \\
78,08\end{array}$ & $\begin{array}{l}2,2 \\
7,8 \\
0,1 \\
3,5 \\
0,3\end{array}$ & & \\
\hline FM B 3 & $\begin{array}{l}\text { Proteínas } \\
\text { Lipídeos } \\
\text { Umidade } \\
\text { Cinzas } \\
\text { Carboidratos }\end{array}$ & $\begin{array}{c}6,77 \\
3,08 \\
11,95 \\
0,75 \\
77,45\end{array}$ & $\begin{array}{l}5,4 \\
7,5 \\
0,3 \\
3,6 \\
0,3\end{array}$ & $\begin{array}{l}\text { Proteínas } \\
\text { Lipídeos } \\
\text { Umidade } \\
\text { Cinzas } \\
\text { Carboidratos }\end{array}$ & $\begin{array}{l}8 \\
2 \\
11 \\
0,6 \\
72\end{array}$ \\
\hline FM B 4 & $\begin{array}{l}\text { Proteínas } \\
\text { Lipídeos } \\
\text { Umidade } \\
\text { Cinzas } \\
\text { Carboidratos }\end{array}$ & $\begin{array}{c}6,77 \\
2,81 \\
11,87 \\
0,64 \\
77,91\end{array}$ & $\begin{array}{c}4,0 \\
10,2 \\
0,5 \\
9,2 \\
0,2\end{array}$ & & \\
\hline FM B 5 & $\begin{array}{l}\text { Proteínas } \\
\text { Lipídeos } \\
\text { Umidade } \\
\text { Cinzas } \\
\text { Carboidratos }\end{array}$ & $\begin{array}{c}6,60 \\
3,23 \\
11,71 \\
0,80 \\
77,65\end{array}$ & $\begin{array}{l}2,1 \\
7,7 \\
0,3 \\
5,6 \\
0,2\end{array}$ & & \\
\hline
\end{tabular}

M-média; \% CV - coeficiente de variação; FM - farinha de milho FM B- marca, FM B (1-5) - lote
TABELA VI - Composição centesimal obtida e valores declarados nos rótulos de farinhas de milho FM C

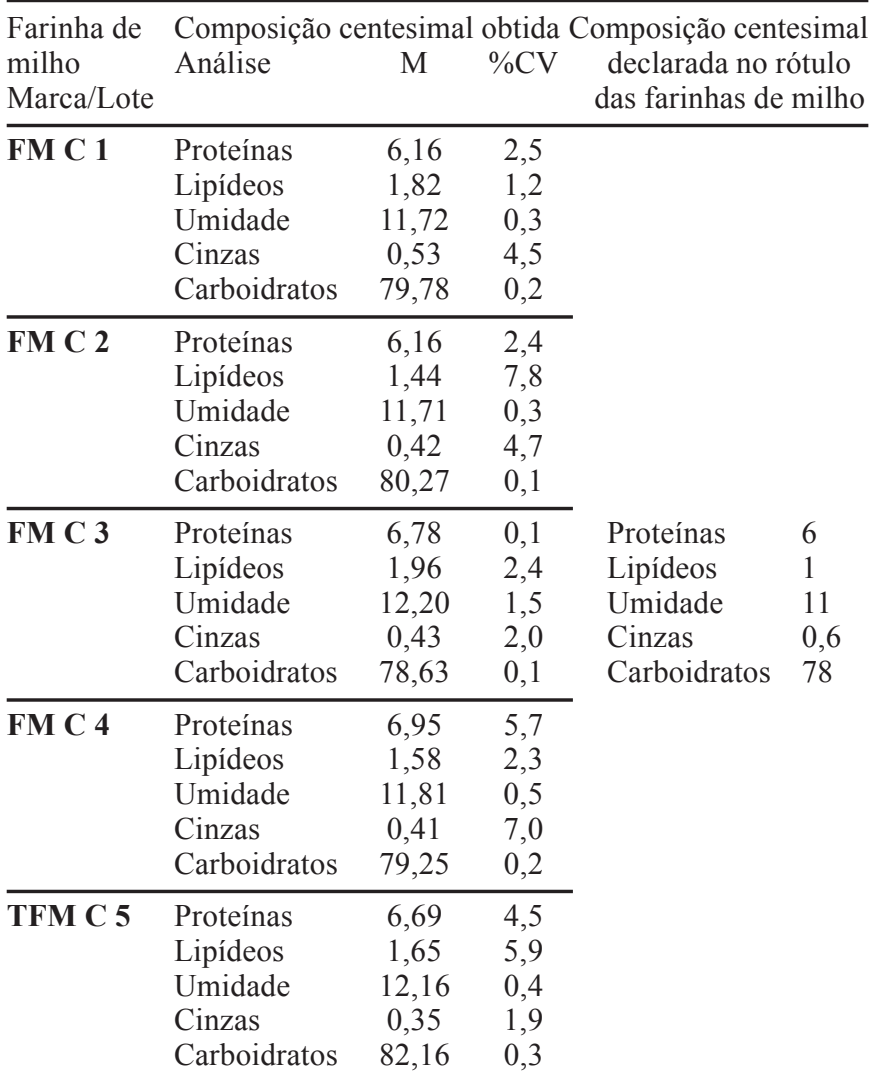

$\mathrm{M}$ - média; \% CV - coeficiente de variação; FM - farinha de milho, FM $\mathrm{C}$ - marca, FM C (1-5) - lote

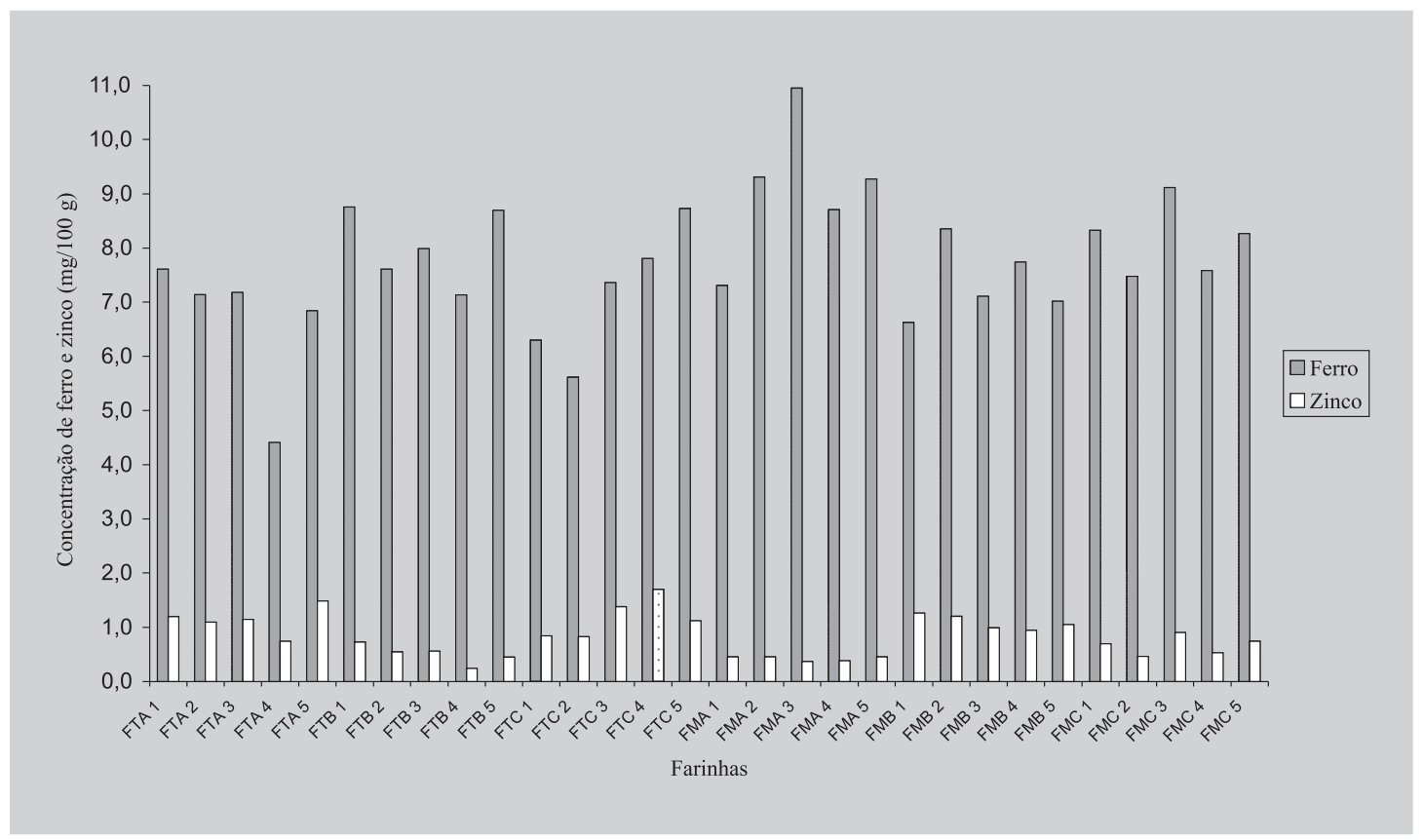

FIGURA I - Ferro e zinco em farinhas de trigo e milho 
ção do mineral nas farinhas está superior ao valor indicado pela Legislação. Entre as marcas de farinhas de milho, existe diferença significativa para as concentrações de ferro obtidas. Já para as farinhas de trigo os valores não são significativamente diferentes, com nível de $95 \%$ de probabilidade (análise de variância, Programa Origin 6.1).

\section{CONCLUSÕES}

Foi possível concluir que apesar da qualidade físicoquímica das farinhas de trigo e milho estar de acordo com as normas vigentes, as mesmas apresentaram teor de ferro muito superior ao esperado.

\section{ABSTRACT \\ Evaluation of iron and zinc content and centesimal composition of enriched wheat and corn flours}

The aim of this work was to evaluate iron and zinc content and centesimal composition of enriched wheat and corn flours. For iron and zinc evaluation the Flame Atomic Absorption Spectrometry was applied. Official methods of analysis were used for moisture, ash, proteins, carbohydrates and lipids. The obtained data were compared with values in the label of products and the specification recommended by Brazilian Legislation. Iron content was higher than those for most of samples. The amount of zinc varied between 0.6 e $1.5 \mathrm{mg} / 100 \mathrm{~g}$. The evaluated flours presented physical-chemistry characteristics according to Legislation. However, about products label was the variation between obtained and presented in package values, for some samples, was confirmed. The obtained results are very important to achieve the objectives of the mandatory enrichment of flours.

UNITERMS: Enriched flours/quantitative analysis. Iron/ determination. Zinc/determination. Centesimal composition.

\section{AGRADECIMENTOS}

Os autores agradecem à Fundação de Amparo à Pesquisa do Estado de São Paulo (Fapesp) pelo financiamento do projeto (Processo 04/02664-4) e pela concessão de bolsa para Programa de Jovem Pesquisador em Centro Emergente (Processo 04/14413-6) e ao Sindicato do Trigo do Estado de São Paulo, pela bolsa de Iniciação Científica.

\section{REFERÊNCIAS BIBLIOGRÁFICAS}

ANVISA. Agência Nacional de Vigilância Sanitária. 2006. Legislação em Vigilância Sanitária. Disponível em: $<$ www.anvisa.gov.br/e-legis >. Acesso em: 10 mar. 2006.

AOAC INTERNATIONAL. Official methods of analysis. $16^{\mathrm{a}}$ ed., $3^{\mathrm{a}}$ rev. Gaitherburg: Published by AOAC International, 1997. v.2, cap. 32, p.1-43.

FERREIRA, A. L. A., MATSUBARA, L. S. Radicais livres: conceitos, doenças relacionadas e estresse oxidativo. Rev. Ass. Med. Brasil, v. 43, p. 61-68.

GUTKOSKI, L. C., JACOBSEN NET, R. Procedimento para teste laboratorial de panificação - pão tipo forma. Ciên. Rur., v.32, p. 873-879, 2002.

HENRIQUES, G. S., HIRATA, M. H., COZZOLINO, S. M. F. Aspectos recentes da absorção e biodisponibilidade do zinco e suas correlações com a fisiologia da isoforma testicular da Enzima Conversora de Angiotensina. Rev. Nutr., v.16, p. 333-345, 2003.

JENNER, P., OLANOW, C. W. Oxidative stress and the pathogenesis of Parkinson's disease. Neurology, v.47, p.S161-S170, 1996.

LOBO, A. S., TRAMONTE, V. L. C. Efeitos da suplementação e da fortificação de alimentos sobre a biodisponibilidade de minerais. Rev. Nutr., v. 7, p. 107113, 2004.

PEDROSA, L. F. C., COZZOLINO, S. M. F. Efeito da suplementação com ferro na biodisponibilidade de zinco em uma dieta regional do nordeste do Brasil. Rev. Saúde Públ., v.27, n.4, p. 266-270, 1993.

RASPER, V. F. Quality evaluation of cereal and cereal products. In: LORENZ, K.J.; KULP, K., eds. Handbook of cereal science and technology. New York: Marcel Dekker, 1991. p. 595-638.

REILLY, C. Too much of a good thing? The problem of a trace element fortification of foods. Trends Food Sci. Technol., v.7, p. 139-142, 1996.

SENA, K. C. M., PEDROSA, L. F. C. Efeitos da suplementação com zinco sobre o crescimento, sistema imunológico e diabetes. Rev. Nutr., v. 18, p. 251-259, 2005. 
SOLOMONS, N. W. Competitive interaction of iron and zinc in diet: consequences for human nutrition. J. Nutr., v.116, p. 927-935, 1986.

TACO. Tabela Brasileira de Composição de Alimentos. 20006. Disponível em: <www.unicamp.br/nepa/taco>. Acesso em: 05 ago. 2006.
TAPIEIRO, H.; GATE, L.; TEW, K. D. Iron: deficiences and requeriments. Biom. Pharmacother., v.55, p. 324-332, 1991.

Recebido para publicação em 25 de outubro de 2006. Aceito para publicação em 03 de setembro de 2007. 